\title{
Effect of hydrochlorothiazide on serum uric acid concentration : a genome-wide association study
}

\section{Ala-Mutka, Eero M.}

2018-04

Ala-Mutka , E M , Rimpelä , J M , Fyhrquist , F , Kontula , K K \& Hiltunen , T P 2018 , ' Effect of hydrochlorothiazide on serum uric acid concentration : a genome-wide association study ' , Pharmacogenomics , vol. 19 , no. 6 , pp. 517-527 . https://doi.org/10.2217/pgs-2017-0184

http://hdl.handle.net/10138/326994

https://doi.org/10.2217/pgs-2017-0184

acceptedVersion

Downloaded from Helda, University of Helsinki institutional repository.

This is an electronic reprint of the original article.

This reprint may differ from the original in pagination and typographic detail.

Please cite the original version. 


\title{
Effect of hydrochlorothiazide on serum uric acid concentration: a genome-wide association study
}

\author{
Eero M Ala-Mutka ${ }^{1}$, Jenni M Rimpelä ${ }^{1,2}$, Frej Fyhrquist ${ }^{3}$, Kimmo K Kontula ${ }^{1,2}$ \& Timo P \\ Hiltunen ${ }^{*}, 1,2$
}

${ }^{1}$ Department of Medicine, University of Helsinki, Helsinki, Finland

${ }^{2}$ Helsinki University Hospital, Helsinki, Finland

${ }^{3}$ Minerva Foundation Institute for Medical Research, Helsinki, Finland [Query-Q4: Shikhil Vyas(CE) to All(AU)] Please provide the name of department in affiliations 2 and 3.

*Author for correspondence: Tel.: +358 504270 152; timo.hiltunen@hus.fi

\begin{abstract}
Aim: To recognize genetic associations of hydrochlorothiazide-induced change in serum uric acid (SUA) concentration. Patients \& methods: We conducted a genome-wide association study on hydrochlorothiazide-induced change in SUA in 214 Finnish men from the GENRES study. Replication analyses were performed in 465 Finns from the LIFE study. Results: In GENRES, we identified 31 loci associated with hydrochlorothiazide-induced change in SUA at $p<5 \times 10^{-5}$. rs1002976 near VEGFC associated with the change in GENRES and in LIFE. rs950569 near BRINP3 associated with the change in SUA in GENRES and LIFE. The analysis of previously reported SNPs and candidate genes provided some proof for PADI4 and ABCC4. Conclusion: We report genetic markers that may predict the increase in SUA concentration during thiazide treatment.
\end{abstract}

\section{Keywords:}

hydrochlorothiazide $\cdot$ pharmacogenomics $\bullet$ uric acid

Uric acid is the end product of endogenously produced and ingested purines in humans. Association of serum uric acid concentration with cardiovascular events has been demonstrated in numerous studies $[1,2]$. 
Pharmacological lowering of serum uric acid concentrations in hypertensive older adults with xanthine oxidase inhibitor allopurinol may lower blood pressure (BP) [3] and decrease risk of stroke and myocardial infarction [4]. However, in some other studies, allopurinol has not had favorable effect on cardiovascular outcomes $[5,6]$.

Increase in serum uric acid concentration is a common side effect of thiazide diuretic treatment, and the utmost manifestation of this side effect is provocation of symptomatic gout [7]. The increase may be caused by volume depletion [8], increased tubular reuptake of uric acid through SLC22A11 [9] and reduced ABCC4mediated secretion of uric acid in urine [10].

Large genome-wide studies have identified several genetic loci associated with serum uric acid concentrations [11] but only one genome-wide study on the effect of thiazide diuretics on serum uric acid concentration has been published [12]. This prompted us to conduct a genome-wide association study (GWAS) on the effect of hydrochlorothiazide (HCTZ) monotherapy on serum uric acid concentrations in the pharmacogenetic Genetics of Drug Responsiveness in Essential Hypertension (GENRES) study. Replication analysis of the most significant results was carried out in Finnish patients of the Losartan Intervention For End point Reduction in Hypertension (LIFE) study.

\section{Patients \& methods}

\section{Study design}

The design and accomplishment of the discovery study, GENRES, have been described previously [13]. Briefly, the GENRES study is a randomized, double-blind, placebo-controlled, cross-over study with four different antihypertensive monotherapies. All 4-week antihypertensive treatment periods were preceded by 4-week placebo periods (Supplementary Figure 1). The study drugs were HCTZ 25 mg, bisoprolol 5 mg, losartan 50 mg and amlodipine $5 \mathrm{mg}$, all once daily. Serum samples were drawn after each treatment and placebo period. The study subjects were 35- to 60-year-old Finnish men with hypertension and no significant comorbidities [13]. For the current study, we selected 214 subjects whose serum samples from at least one placebo period and from the HCTZ treatment period were available, and who were successfully genotyped (see below). The flowchart of the selection of the subjects for the present study is illustrated in Supplementary Figure 2. No episodes of gout emerged during the study.

The design of the replication study, LIFE, has been described previously [14]. The LIFE study is a randomized, double-blind study performed in Denmark, Finland, Norway, Sweden, UK and USA. Inclusion criteria were age of 55 to 80 years, office systolic BP $160-200 \mathrm{mmHg}$ or diastolic BP $95-115 \mathrm{mmHg}$, and signs of left ventricular hypertrophy in electrocardiography. Patients with following conditions were excluded: secondary hypertension, myocardial infarction or stroke within the preceding 6 months, beta-blocker- or calcium-antagonist-treated angina pectoris, heart failure, ejection fraction less than $40 \%$, or other diseases treated with beta-blockers, angiotensin II type 1 receptor antagonists, thiazides or angiotensin-converting enzyme inhibitors. Patients were randomly assigned to treatment with losartan (50 mg daily) or atenolol (50 mg daily) after a 2-week placebo period. HCTZ $12.5 \mathrm{mg}$ daily was then added to the treatment if target BP, less than $140 / 90 \mathrm{mmHg}$, was not achieved. Later 
treatment escalations included increase of the study drug dose to $100 \mathrm{mg}$, increase of HCTZ dose to $25 \mathrm{mg}$ and addition of other antihypertensive drugs. However, only subjects using $12.5 \mathrm{mg}$ of HCTZ were included in the present study (see below).

Total number of patients in the LIFE study was 9193 [14]. A pharmacogenetic substudy was done in 3503 Scandinavian patients [15]. They included 1146 Finnish patients whose samples were available for GWAS [16]. In order to qualify into the replication analysis, the LIFE patients were required to be screened for serum uric acid level at the commencement of the study and 1 year after, and antihypertensive drug treatments needed to be intensified with a thiazide during the first year of the study to reach the BP targets; no patients were on HCTZ monotherapy. Accordingly, we chose patients using treatment of the first two titration steps (12.5 mg of HCTZ with 50 or $100 \mathrm{mg}$ of the study drugs losartan/atenolol) at year 1 of the study. Initially, there were 557 patients with such treatment. We excluded 33 patients due to low success rate in genotyping, ambiguity in gender check or first-degree relativeness, 40 patients due to missing serum uric acid values at baseline or year 1 , eight patients with chronic kidney disease (creatinine clearance $<30 \mathrm{ml} / \mathrm{min} / 1.73 \mathrm{~m}^{2}$ or urine microalbumin $>300 \mathrm{mg} / \mathrm{l}$ ), eight patients with morbid obesity (body mass index $>40 \mathrm{~kg} / \mathrm{m}^{2}$ ), and three patients with change in serum uric acid concentration deviating more than four SDs from the mean. [Query-Q5: Shikhil Vyas(CE) to All(AU)]Please define the following term: 'SD'. The flowchart of the selection of the subjects for the present study is illustrated in Supplementary Figure 3. The resulting 465 Finnish LIFE patients included in the replication analyses are listed according to their type of LIFE study treatment in Supplementary Table 1. The type of study treatment was included as covariate in the replication analyses as described in 'Statistical analysis'.

\section{Measurement of serum uric acid concentration}

The serum samples of the GENRES study were stored at $-80^{\circ} \mathrm{C}$. Serum uric acid concentrations were measured in 2013, in other words, 9 years after the end of the clinical study (2004) in a single batch in the clinical laboratory of the Helsinki University Hospital using an enzymatic photometric method. It is possible that serum samples of a portion of subjects were thawed temporarily during the storage due to freezer failure. Therefore, we compared the serum uric acid results from the single-batch analysis with results from freshly-analyzed unfrozen serum samples drawn after the first placebo period. Pearson correlation coefficient between the two results was 0.98 and the corresponding Cronbach's alpha 0.99, which indicates excellent reproducibility and therefore demonstrates the appropriateness of all long-term frozen samples for the present study.

Serum uric acid concentrations in the LIFE subjects were measured using PAP uricase method on DAX96analyzer (Hitachi 717 analyzer, Boehringer Mannheim, Mannheim, Germany).

\section{Genotyping}

The DNA samples of the GENRES study were genotyped using Illumina HumanOmniExpress-12 BeadChip (Illumina, Inc., CA, USA) at the Institute for Molecular Medicine Finland, University of Helsinki as described previously [17]. For the analysis of the most relevant SNPs of the earlier study of Vandell et al. [12], four SNPs were imputed in GENRES using IMPUTE2 (version 2.2.2) and the HapMap release 22. 
The samples of the 1146 LIFE study patients were genotyped using the same Illumina HumanOmniExpress BeadChip (Illumina) at the Institute for Molecular Medicine Finland, University of Helsinki as described previously [16]. Individual samples were discarded due to low success rate $(<95 \%)$ or gender ambiguity (see above).

\section{Statistical analysis}

For genome-wide association analysis of HCTZ-induced change in serum uric acid concentration in GENRES, we generated residuals using stepwise linear regression in IBM SPSS Statistics program (version 22.0, SPSS, Inc., IL, USA). We calculated the concentration change as the value after HCTZ treatment minus the mean value after all placebo periods. Four placebo values were available for 187, three for 22, two for two and one for three subjects. Using stepwise linear regression with $p<0.10$ as an inclusion criterion, we included baseline serum uric acid concentration $(p=0.03)$ and current smoking $(p=0.09)$ as covariates for the calculation of residuals (Supplementary Table 2). Covariates tested but not included $(p>0.10)$ were age, duration of hypertension (years), serum creatinine concentration, creatinine clearance $1.73 \mathrm{~m}^{2}$; and body mass index. We used PLINK v.1.07 under an additive genetic model for the genome-wide association analysis [18]. We excluded SNPs with minor allele frequency $<0.01$ or Hardy-Weinberg equilibrium $p<1 \times 10^{-5}$ from the analyses.

From the genome-wide association analysis of GENRES, we selected SNPs with $p<5 \times 10^{-5}$ (representing 31 loci) for replication analysis in Finnish LIFE patients. We calculated residuals for the change in serum uric acid concentration at year 1 of the study using linear regression and the following covariates: gender, treatment arm, baseline serum uric acid concentration and age (Supplementary Table 3). We used PLINK and additive genetic model for the replication analyses. We defined successful replication as Bonferroni-corrected p-value of 0.0016 $(=0.05 / 31)$ and the same direction of effect as observed in GENRES. The data are presented as mean \pm SD unless otherwise indicated. Because the study subjects of the discovery cohort (GENRES) were all men, a separate association analysis was performed in men in LIFE if SNP-by-sex interaction was significant $(p<0.05)$.

We used a SNP set-based method in GENRES to test the association of candidate genes (SLC22A11 and $A B C C 4$ ) with HCTZ-induced elevation of serum uric acid. We included all successfully genotyped SNPs located within $100 \mathrm{~kb}$ of the genes (40 SNPs for SLC22A11 and 447 for ABCC4). For the analysis, we used PLINK with additive genetic model and residuals of HCTZ-induced change in serum uric acid, generated as described above. Single SNP was included if $p$-value was $<0.05$ and $r^{2}$ with other included SNPs was $<0.5$. The maximum number of included SNPs was limited to five for each gene. For determination of empirical p-value, the data was permuted 10,000-times for each gene.

\section{Results}

\section{Study subjects}

The baseline characteristics of the subjects included in the current study are presented in Table 1. Mean baseline serum uric acid concentrations of the GENRES and LIFE patients were similar, 357 and $335 \mu \mathrm{mol} / \mathrm{l}$, respectively. Compared with GENRES, the patients of the LIFE study were older, had higher systolic BP, included also women 
(54\%) and fewer of them were current smokers. [Query-Q6: Shikhil Vyas(CE) to All(AU)] Please check and confirm that any figures/tables that appear in the article have been redrawn correctly, and if not, please describe any corrections that need to be made.

Table 1. Baseline data of the study subjects.

\begin{tabular}{|c|c|c|}
\hline [Query-Q7: Shikhil Vyas(CE) to All(AU)] Please provide column head here. & GENRES & LIFE \\
\hline Number of subjects & 214 & 465 \\
\hline $\operatorname{Men}(n / \%)$ & $214 / 100$ & $216 / 46^{\ddagger}$ \\
\hline Age (years) & $50.5(6.4)$ & $64.0(6.4)^{\ddagger}$ \\
\hline Body mass index $\left(\mathrm{kg} / \mathrm{m}^{2}\right)$ & $26.6(2.8)$ & $28.1(3.7)^{\ddagger}$ \\
\hline Baseline serum uric acid $(\mu \mathrm{mol} / \mathrm{l})$ & $357(59)$ & $335(68)^{\ddagger}$ \\
\hline Hyperuricemic before study $^{\dagger}(\mathrm{n} / \%)$ & $2 / 1$ & $29 / 6^{\ddagger}$ \\
\hline Office systolic BP (mmHg) & $152(13)$ & $172(13)^{\ddagger}$ \\
\hline Office diastolic BP $(\mathrm{mmHg})$ & $100(6.7)$ & $99(7.7)$ \\
\hline Current smokers $(\mathrm{n} / \%)$ & $36 / 17$ & $55 / 12$ \\
\hline Serum creatinine $(\mu \mathrm{mol} / \mathrm{l})$ & $86(13)$ & $80(13)^{\ddagger}$ \\
\hline Serum glucose $(\mathrm{mmol} / \mathrm{l})$ & $5.4(0.6)$ & $5.6(1.4)^{\ddagger}$ \\
\hline
\end{tabular}

Data are presented as mean (standard deviation).

Serum uric acid $>480 \mu \mathrm{mol} / \mathrm{l}$ in men and $>400 \mu \mathrm{mol} / \mathrm{l}$ in women over 50 years of age.

$\ddagger p<0.05$ between GENRES and LIFE, analyzed with Student's t-test for linear variables and with Fisher's exact test for categorical variables.

BP: Blood pressure.

\section{Effect of HCTZ on serum uric acid}

During the 4-week monotherapy with $25 \mathrm{mg}$ of HCTZ in GENRES, the mean increase of serum uric acid concentration was $50 \pm 39 \mu \mathrm{mol} / \mathrm{l}\left(\mathrm{p}=4.6 \times 10^{-47}\right.$ in paired t-test; Supplementary Table 4). For comparison, losartan and amlodipine caused decreases (28 and $22 \mu \mathrm{mol} / \mathrm{l}$, respectively) of serum uric acid level, while bisoprolol treatment increased serum uric acid level slightly (Supplementary Table 4).

In LIFE, an increase (49 $\pm 60 \mu \mathrm{mol} / \mathrm{l})$ of serum uric acid level was seen in patients treated with atenolol (50 or $100 \mathrm{mg}$ ) and HCTZ $12.5 \mathrm{mg}$ at year 1 of the study ( $p=1.0 \times 10^{-26}$ in paired t-test) (Supplementary Table 1). In LIFE patients treated with losartan (50 or $100 \mathrm{mg}$ ) and HCTZ $12.5 \mathrm{mg}$, serum uric acid concentration increased nonsignificantly $(5.4 \pm 55 \mu \mathrm{mol} / \mathrm{l} ; \mathrm{p}=0.13)$.

\section{Genome-wide association analysis of HCTZ-induced change in serum uric acid in GENRES}

The quantile-quantile plot of the genome-wide association analysis of HCTZ-induced change in serum uric acid concentration in GENRES (Supplementary Fig. 4) shows little evidence for genomic inflation and provides some support for the existence of significant associations. The Manhattan plot of the analysis indicates some potentially interesting signals although no SNP reached genome-wide significance $\left(p<5 \times 10^{-8}\right)$ (Figure 1). The lowest pvalue was obtained for rs2884594 on chromosome 12 near FGF23 (Supplementary Table 5). The 31 loci with p $<5 \times 10^{-5}$ (Supplementary Table 5) were selected for replication analysis in the LIFE study cohort. 


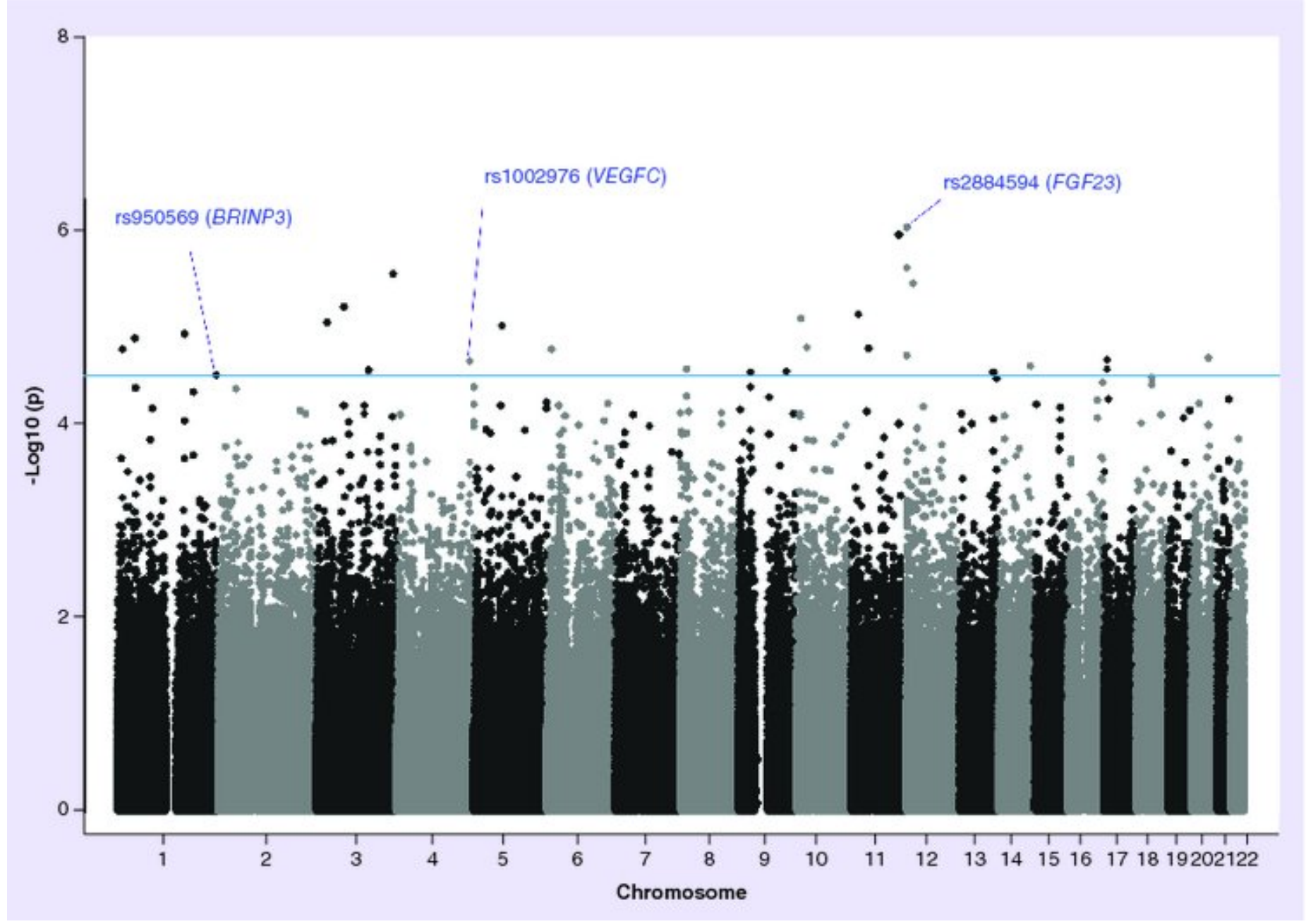

Figure 1. XXX [Query-Q8: Shikhil Vyas(CE) to All(AU)] Please provide a general/main title for Figure 1.

\section{Replication analysis in LIFE}

The replication analyses of the 31 most significant loci in GENRES carried out in LIFE subjects treated with HCTZ (and 50 or $100 \mathrm{mg}$ of atenolol or losartan) are summarized in detail in Supplementary Table 5. The lowest p-value $\left(p=3.6 \times 10^{-4}\right)$ was obtained for rs1002976 on chromosome 4 near VEGFC, reaching the Bonferroni-corrected significance level $\left(p<1.6 \times 10^{-3}\right)$. rs950569 on chromosome 1 near BRINP3 was also associated with change in serum uric acid concentration in LIFE with a p-value of $2.6 \times 10^{-3}$, almost reaching the Bonferroni-corrected significance level (Supplementary Table 5). In contrast, rs2884594 near FGF23 associated with the lowest pvalue in GENRES did not replicate in LIFE $(p=0.32$ ). However, $r s 11612082$ which is in linkage disequilibrium (LD) with rs2884594 ( $r^{2}=0.66$ in 1000 Genomes Finns) showed a trend for replication $\left(p=2.0 \times 10^{-5}\right.$ in GENRES; $p=0.084$ in LIFE). SNP-by-sex interaction analysis of the 31 most significant loci in GENRES was carried out in LIFE (Supplementary Table 5). The interaction was significant for one SNP, rs508362 in RREB1. The p-value for the association of serum uric acid change with this SNP was somewhat stronger in men $($ beta $=19.2 \mu \mathrm{mol} / \mathrm{l} ; \mathrm{p}=0.07)$ than in men and women combined (beta $=4.6 \mu \mathrm{mol} / \mathrm{l} ; \mathrm{p}=0.5$ ).

Regional Manhattan plots for the two loci with the most consistent replication data are illustrated in Figures 2 and 3. rs 1002976 is located approximately $27 \mathrm{~kb}$ downstream of VEGFC, while rs950569 is located $226 \mathrm{~kb}$ downstream of BRINP3. 


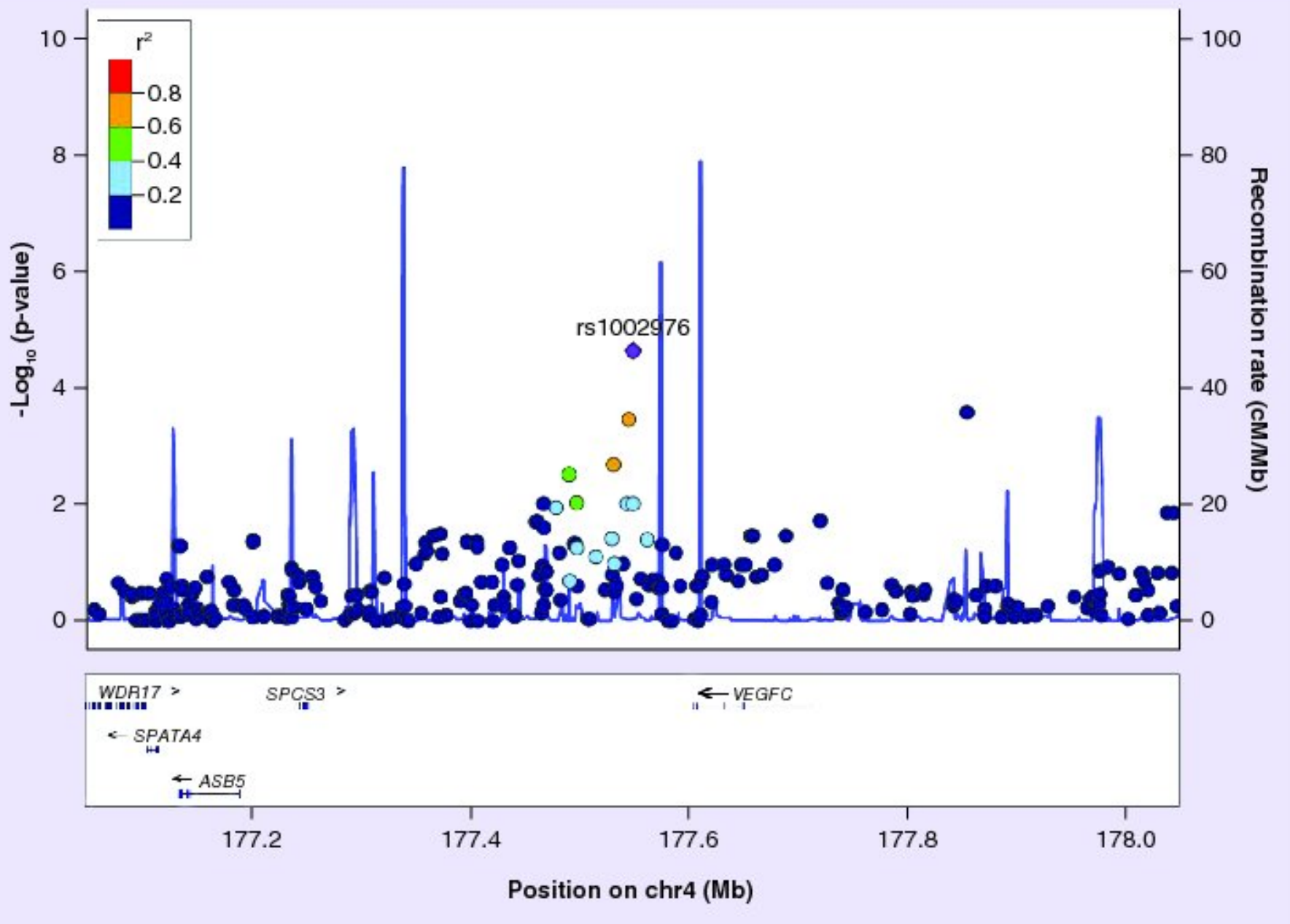

Figure 2. $X X X[Q u e r y-Q 9$ : Shikhil Vyas(CE) to All(AU)] Please provide a general/main title for Figure 2.

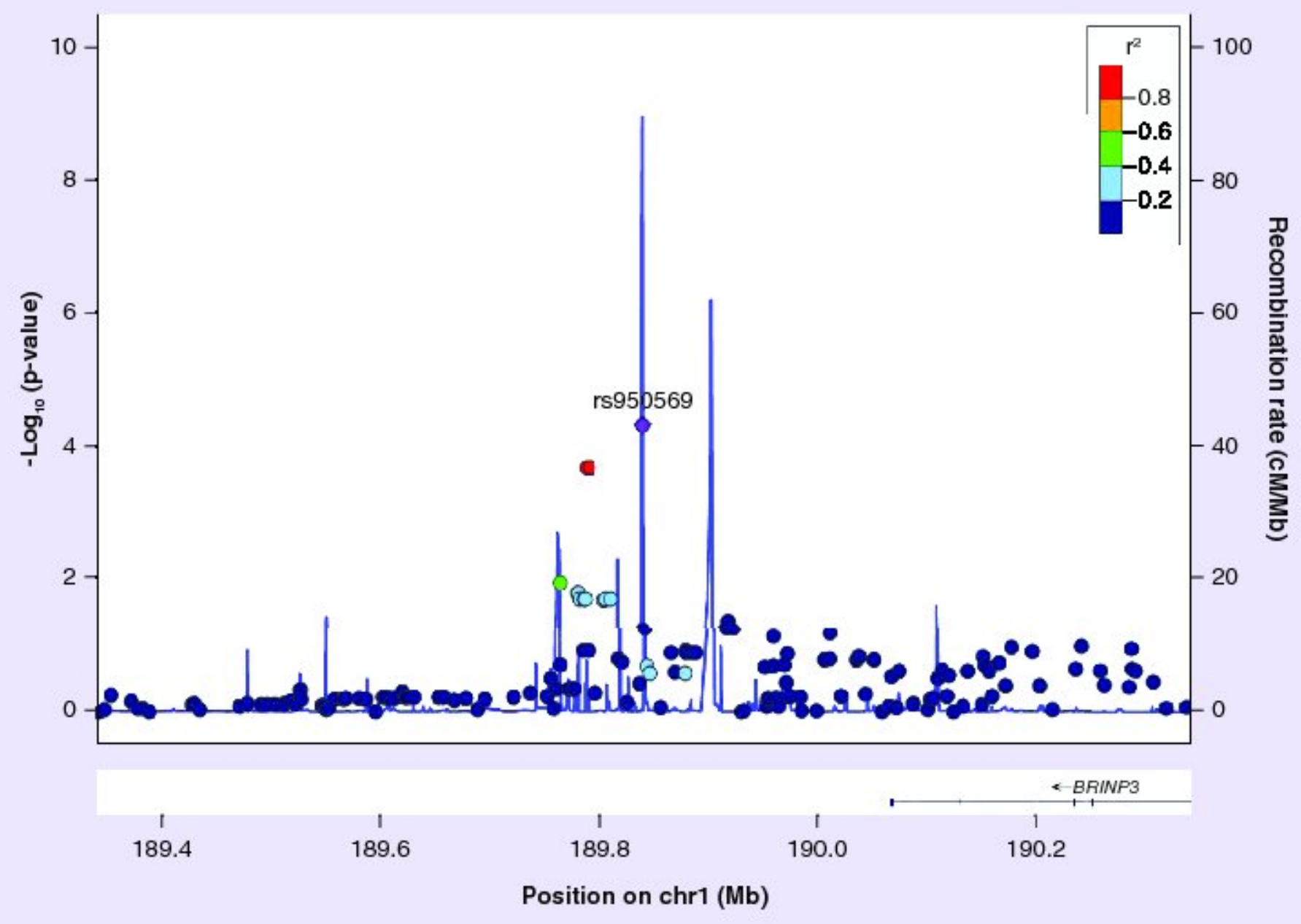


Figure 3. $\quad X X X[Q u e r y-Q 10:$ Shikhil Vyas(CE) to All(AU)] Please provide a general/main title for Figure 3.

Associations of rs1002976 and rs950569 genotypes with HCTZ-induced changes in serum uric acid concentration in GENRES and LIFE are illustrated in Figures 4 and 5. In both cases, a significant gene-dosage type of effect was observed upon genotype comparisons. Cluster plots of genotyping of rs1002976 and rs950569 are presented in Supplementary Figure 5. [Query-Q11: Bethany Lucey(PE) to All(AU)]Please could you let me know if you would like your figures printed in colour? The cost of colour printing is UK£155 per figure, with a discount for articles with two or more figures. Thus, the price to print all your figures in colour is $£ 535$.
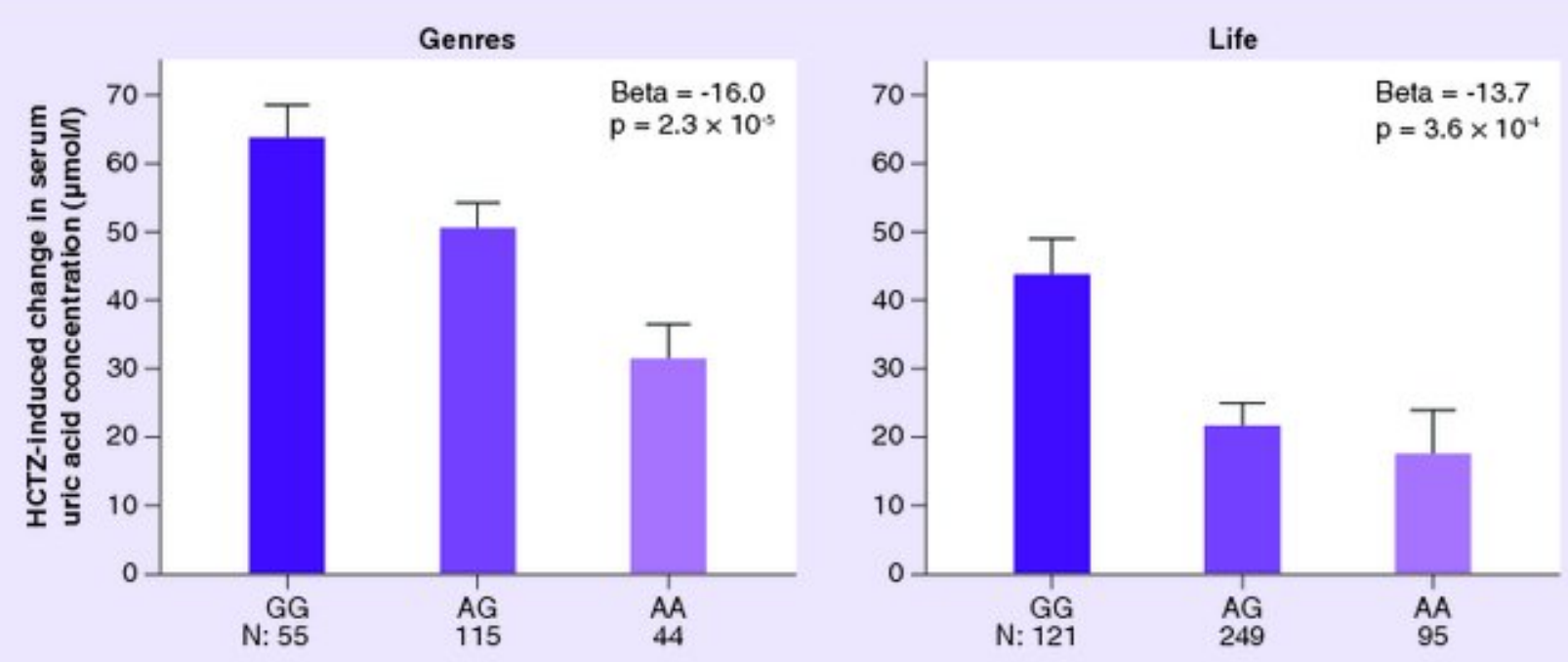

Figure 4. XXX[QQery-Q12: Shikhil Vyas(CE) to All(AU)] Please provide a general/main title for Figure 4. HCTZ: Hydrochlorothiazide.
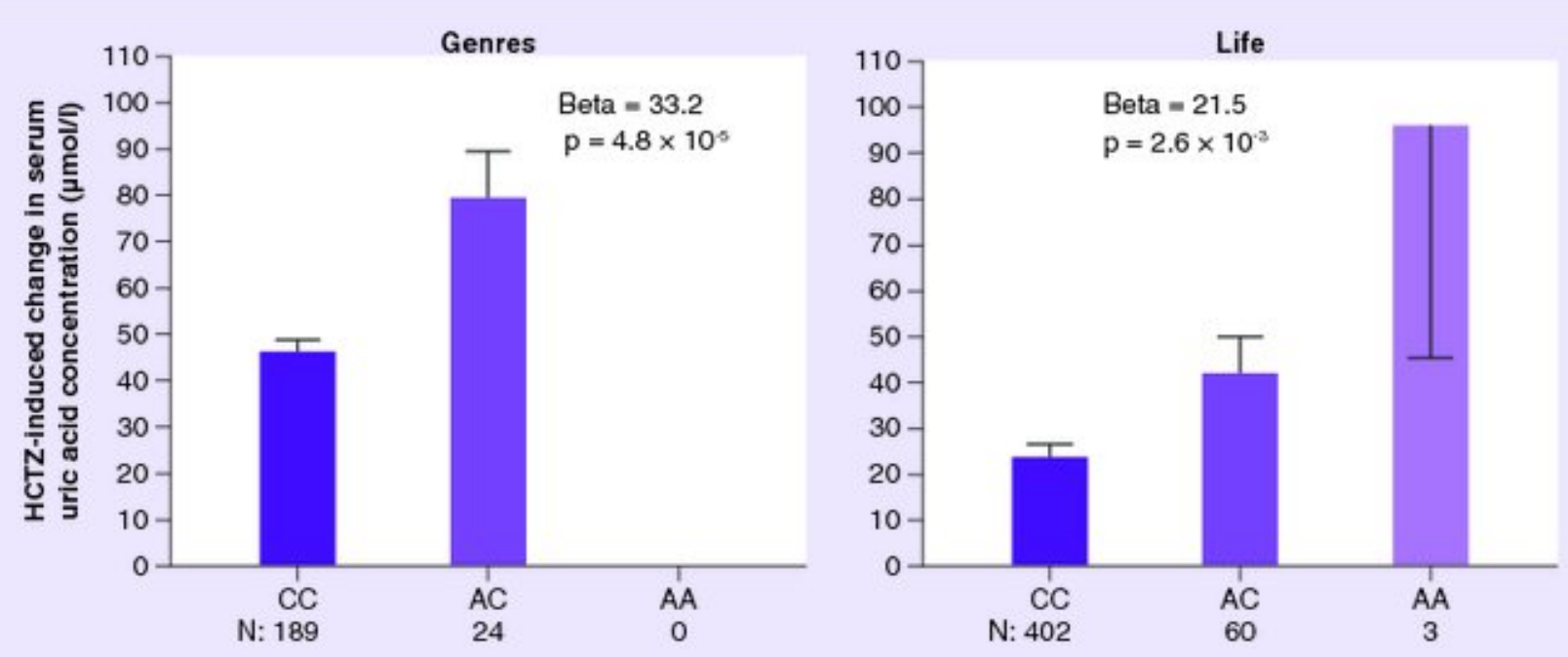

Figure 5. $\quad X X X$ [Query-Q13: Shikhil Vyas(CE) to All(AU)] Please provide a general/main title for Figure 5.

HCTZ: Hydrochlorothiazide.

\section{Analysis of the most significant results derived from an earlier GWAS}

In an earlier GWAS study [12], altogether six SNPs, one in Caucasians and five in African Americans, were associated with HCTZ-induced change in serum uric acid concentration. Among those reported in African Americans (Supplementary Table 6), rs2477134 showed some evidence of association in GENRES (beta = 
-9.3 $\mathrm{\mu mol} / \mathrm{l} ; \mathrm{p}=0.016)$. rs2477134 is located on chromosome 1 near PADI4. The SNP rs1418243 reported positive for Caucasians did not replicate in our study (Supplementary Table 6).

\section{Analysis of the association of candidate genes with HCTZ-induced elevation of serum uric acid}

In the SNP set-based test for $A B C C 4$ in GENRES, the combined p-value for the five most significant SNPs was 0.055 (Supplementary Table 7). The top SNP ( $r$ s9561863; $\mathrm{p}=5.6 \times 10^{-4}$ ) is located $74 \mathrm{~kb}$ upstream from ABCC4. The other four SNPs are intronic. Within $100 \mathrm{~kb}$ of SLC22A11 no SNP was associated with uric acid change with $p<0.05$.

\section{Discussion}

In the current study, we searched for SNPs associated with HCTZ-induced increase in serum uric acid concentration. In the genome-wide analysis of the discovery cohort (GENRES), no SNP reached genome-wide significance but 31 potential loci of interest $\left(p<5 \times 10^{-5}\right)$ were identified. Using the replication cohort (the Finnish subjects of the LIFE study), we obtained support for two of these loci. In addition, analysis of results from an earlier study [12] as well as SNP set-based analysis of two candidate genes provided potentially significant results. The SNPs showing the strongest association with serum uric acid level in our study had effect sizes of ca. 10-20 $\mu \mathrm{mol} / \mathrm{l}$ per allele. Whether this magnitude reflects clinical significance is presently unknown, but it is of interest that an increase of $60 \mu \mathrm{mol} / \mathrm{l}$ in serum uric acid concentration has been proposed to associate with a $15 \%$ increased risk of total and cardiovascular mortality $[19,20]$.

We consider the association of rs 1002976 with change in serum uric acid during HCTZ treatment as the most significant finding of the present study. The association was observed both in the GENRES discovery cohort $\left(\right.$ beta $\left.=-16 \mu \mathrm{mol} / \mathrm{l} ; \mathrm{p}=2 \times 10^{-5}\right)$ and in the Finnish LIFE replication cohort (beta $\left.=-14 \mu \mathrm{mol} / \mathrm{l} ; \mathrm{p}=4 \times 10^{-4}\right)($ Figure 4). rs1002976 is located on chromosome 4 at a distance of $56 \mathrm{~kb}$ from VEGFC, which codes for vascular endothelial growth factor C. The LD block of this SNP does not extend to the actual VEGFC area (Figure 2). [Query-Q14: Shikhil Vyas(CE) to All(AU)] Please define the following term: 'eQTL'. However, eQTL data [21,22] suggest that rs1002976 may be associated with the expression level of VEGFC mRNA ( $p=0.0055$, adrenal gland) [], although $r s 1002976$ itself does not seem to cause any changes in regulatory DNA elements. VEGFC promotes lymphangiogenesis and angiogenesis by binding to VEGFR2 and VEGFR3 [23]. It induces proliferation and survival of endothelial cells [23], and its increased expression has been linked to production of proinflammatory cytokines [24]. Interestingly, thiazide diuretics and VEGFC were related in an earlier study where secretion of VEGFC protein in culture medium by vascular smooth muscle cells was reduced by chlorthalidone and bendroflumethiazide [25]. Regulation of uric acid has also been related to VEGF gene family in an earlier study: its serum levels associated with VEGFA SNPs in a large meta-analysis [11]. VEGFA and VEGFC share the same receptor, VEGFR2, which probably mediates most of the vascular effects of VEGFs [26].

rs950569 on chromosome 1 associated with change in serum uric acid in the GENRES discovery cohort (beta $=33 \mu \mathrm{mol} / / ; p=5 \times 10^{-5}$ ), while in the LIFE replication cohort the association (beta $=21 \mu \mathrm{mol} / \mathrm{l} ; \mathrm{p}=0.003$ ) did not quite meet the Bonferroni-corrected significance level (Figure 5). This SNP is located on an intergenic 
area close to a lincRNA gene. The closest gene with known function is BRINP3 (Figure 3), which codes for protein 'BMP/retinoid acid inducible neural specific 3'. BRINP3 is involved in the development and maintenance of nervous system [27,28]. BRINP3 may also be a marker of inflammation [28]. To our knowledge, BRINP3 has not earlier been associated with uric acid metabolism. In dbGaP, rs950569 is reported to associate with results from platelet function tests [29].

rs2884594 reached the most significant association in GENRES (beta $=20 \mu \mathrm{mol} / \mathrm{l} ; \mathrm{p}=9.5 \times 10^{-7}$ ). One SNP from the same locus was to some extent replicated in LIFE (Supplementary Table 5). The closest gene of this locus is FGF23, which codes for fibroblast growth factor 23 . FGF23 is a regulator of kidney phosphate and vitamin D metabolism and it is produced mainly in bone [30]. Interestingly, serum FGF23 levels have been shown to associate with serum uric acid concentrations and uric acid clearance [31-33].

Six other SNPs previously associated with HCTZ-induced change in serum uric acid concentration were also tested in our study [12]. Some support for the association was obtained for rs2477134 in our GENRES study (Supplementary Table 6). This SNP is located $1 \mathrm{~kb}$ away from PADI4 on chromosome 1. PADI4 codes for peptidyl arginine deiminase 4, which catalyzes the deimination of arginine to citrulline. GTExportal.com database indicates that this SNP may be associated with expression level of PADI4 mRNA ( $p=0.0006$, lung) [21]. PADI4 has previously been associated with rheumatoid arthritis and multiple sclerosis [34].

ABCC4 has been suggested to mediate the reduction of urinary uric acid secretion by HCTZ [10]. Some support for possible underlying genetic mechanisms was obtained in the SNP set-based analysis of $A B C C 4$ $( \pm 100 \mathrm{~kb})$ in GENRES $(p=0.055)$ (Supplementary Table 7). There is scarce earlier data on ABCC4 genetic variation and metabolism of uric acid: rs12870204 (in LD with rs4148455, one of the five SNPs discovered in this study) was weakly associated with serum uric acid concentrations in subjects with normal kidney function [35].

The major strength of the present study lies in the careful design of the GENRES study: it was placebocontrolled and the baseline estimates for serum uric acid concentration were derived from up to four placebo periods for each subject. In addition, any drug-related effects can be controlled for their specificity because four different antihypertensive classes were involved. The replication cohort was of the same ethnic background, and the same genotyping platforms were used in both cohorts. However, our study has some important limitations. First, the sample size of the discovery study (GENRES) was relatively small. Second, both men and women were included in LIFE, whereas GENRES consisted of men only. Third, due to study design, subjects of the Finnish LIFE replication study were unavoidably treated with a combination therapy also including atenolol or losartan, even if the treatment arm was included as a covariate in the analyses. Fourth, the 12.5-mg dose of HCTZ in the replication study was lower than the 25-mg dose in GENRES.

\section{Conclusion}

We have identified a few interesting SNPs that may predict the increase of serum uric acid concentration during HCTZ treatment. Additional studies in other and even larger populations are needed to confirm these data. However, it is not known if the associations translate into clinically significant differences, such as occurrence of 
gout or cardiovascular events during thiazide treatment. [Query-Q15: Bethany Lucey(PE) to All(AU)] Table 2 is not cited in the text, please indicate where this citation should be inserted.

Table 2

Table 2. Summarv of the most significant SNP associations of hydrochlorothiazide-induced increase in serum uric acid concentration.

\begin{tabular}{|c|c|c|c|c|c|c|c|c|c|c|c|c|}
\hline \multirow[t]{2}{*}{ SNP } & \multirow[t]{2}{*}{ Closest gene } & \multirow[t]{2}{*}{ Chr } & \multirow[t]{2}{*}{ Position $^{\dagger}$} & \multirow[t]{2}{*}{ CANCA } & \multicolumn{4}{|c|}{ GENRES $^{\ddagger}$} & \multicolumn{4}{|c|}{ LIFE ${ }^{\S}$} \\
\hline & & & & & $\mathrm{n}$ & CAF & Beta & p-value & $\mathbf{n}$ & CAF & Beta & p-value \\
\hline rs1002976 & VEGFC & 4 & 177548598 & $A / G$ & 214 & 0.47 & -16.0 & $2.3 \times 10^{-5}$ & 465 & 0.48 & -13.7 & $3.6 \times 10^{-4}$ \\
\hline rs950569 & BRINP3 & 1 & 189841077 & $\mathrm{~A} / \mathrm{C}$ & 213 & 0.06 & 33.2 & $4.8 \times 10^{-5}$ & 465 & 0.06 & 21.5 & $2.6 \times 10^{-3}$ \\
\hline
\end{tabular}

Betas are in $\mu \mathrm{mol} / \mathrm{l}$.

Build 37.

Discovery cohort.

Replication cohort.

CA: Coded allele; CAF: Coded allele frequency; Chr: Chromosome; NCA: Noncoded allele.

\section{Summary points}

\section{Background}

- Hyperuricemia is a common side effect of thiazide diuretics.

- A genome-wide association study on the effect of hydrochlorothiazide on serum uric acid concentration was conducted in GENRES subjects and replication analysis of the best results was done in Finnish LIFE subjects.

\section{Results}

- In GENRES, 31 potential genetic loci $\left(p<5 \times 10^{-5}\right)$ were identified.

- $\quad$ rs1002976 near VEGFC was positively replicated in LIFE.

- $\quad$ rs950569 near BRINP3 was replicated with borderline significance in LIFE.

- $\quad$ Some additional support for previously reported rs2477134 near PADI4 was obtained in GENRES.

\section{Conclusion}

- The present study revealed a few novel possible genetic markers of hydrochlorothiazide-induced change in serum uric acid concentration.

\section{Supplementary data}

To view the supplementary data that accompany this paper please visit the journal website at: www.futuremedicine.com/doi/full/10.2217/pgs-2017-0184

\section{Acknowledgements}

The authors thank S Saarinen for excellent technical help. 
Financial \& competing interests disclosure [Query-Q16: Shikhil Vyas(CE) to All(AU)] Please check that the financial disclosure is correct. If you are NIH funded and would like your article to be deposited on the NIHMS system/PMC you must state that here and on your copyright form. Please note that as per PMC's policy, the NIHMS/PMC deposit scheme does not apply if your article is not peer reviewed.

The present study was supported by grants from The Sigrid Juselius Foundation and The Finnish Foundation for Cardiovascular Research. EM Ala-Mutka, JM Rimpelä, F Fyhrquist, KK Kontula and TP Hiltunen have no other relevant affiliations or financial involvement with any organization or entity with a financial interest in or financial conflict with the subject matter or materials discussed in the manuscript apart from those disclosed.

No writing assistance was utilized in the production of this manuscript.

\section{Ethical conduct of research}

The GENRES study was approved by the Ethical Committee of Helsinki University Central Hospital and the National Agency for Medicines of Finland. The study was conducted in compliance with Declaration of Helsinki and Guidelines for Good Clinical Practice. All patients gave signed informed consent before the study. The study is registered at ClinicalTrials.gov (NCT03276598).

All patients of the LIFE signed informed consent before study. The study was conducted in compliance with Declaration of Helsinki and with approval from institutional review board. The study is registered at ClinicalTrials.gov (NCT00338260).

\section{References}

Papers of special note have been highlighted as: • of interest; •• of considerable interest

1. Hoieggen A, Alderman MH, Kjeldsen SE et al. The impact of serum uric acid on cardiovascular outcomes in the LIFE study. Kidney Int. 65(3), 1041-1049 (2004).

- Change in serum uric acid concentration may modulate the effect of antihypertensive treatment on cardiovascular outcomes.

2. Bardin $\mathrm{T}$, Richette P. Impact of comorbidities on gout and hyperuricaemia: an update on prevalence and treatment options. BMC Med. 15(1), 123 (2017).

3. Soletsky B, Feig DI. Uric acid reduction rectifies prehypertension in obese adolescents. Hypertension 60(5), 1148-1156 (2012).

4. Macisaac RL, Salatzki J, Higgins $P$ et al. Allopurinol and cardiovascular outcomes in adults with hypertension. Hypertension 67(3), 535-540 (2016).

5. Kok VC, Horng JT, Chang WS, Hong YF, Chang TH. Allopurinol therapy in gout patients does not associate with beneficial cardiovascular outcomes: a population-based matched-cohort study. PLOS ONE 9(6), e99102 (2014).

6. Soltoft Larsen K, Pottegard A, Lindegaard HM, Hallas J. Impact of urate level on cardiovascular risk in allopurinol treated patients. A nested case-control study. PLOS ONE 11(1), e0146172 (2016).

7. Demartini FE, Wheaton EA, Healey LA, Laragh JH. Effect of chlorothiazide on the renal excretion of uric acid. Am. J. Med. 32(4), 572-577 (1962).

8. Steele $\mathrm{TH}$, Oppenheimer S. Factors affecting urate excretion following diuretic administration in man. Am. J. Med. 47(4), 564-574 (1969).

9. Hagos $Y$, Stein D, Ugele B, Burckhardt G, Bahn A. Human renal organic anion transporter 4 operates as an asymmetric urate transporter. J. Am. Soc. Nephrol. 18(2), 430-439 (2007).

10. El-Sheikh AA, Van Den Heuvel JJ, Koenderink JB, Russel FG. Effect of hypouricaemic and hyperuricaemic drugs on the renal urate efflux transporter, multidrug resistance protein 4. Br. J. Pharmacol. 155(7), 1066-1075 (2008).

11. Köttgen A, Albrecht $E$, Teumer $A$ et al. Genome-wide association analyses identify 18 new loci associated with serum urate concentrations. Nat. Genet. 45(2), 145-154 (2013).

- Large genome-wide association study on the genetics of serum urate concentration.

12. Vandell AG, Mcdonough CW, Gong $Y$ et al. Hydrochlorothiazide-induced hyperuricaemia in the pharmacogenomic evaluation of antihypertensive responses study. J. Int. Med. 276(5), 486-497 (2014).

- The first genome-wide association study on hydrochlorothiazide-induced change in serum urate concentration. 
13. Hiltunen TP, Suonsyrjä T, Hannila-Handelberg $T$ et al. Predictors of antihypertensive drug responses: initial data from a placebo-controlled, randomized, cross-over study with four antihypertensive drugs (the GENRES study). Am. J. Hypertens. 20(3), 311-318 (2007).

14. Dahlof B, Devereux RB, Kjeldsen SE et al. Cardiovascular morbidity and mortality in the Losartan Intervention For Endpoint reduction in hypertension study (LIFE): a randomized trial against atenolol. Lancet 359(9311), 995-1003 (2002).

15. Nordestgaard BG, Kontula K, Benn M et al. Effect of ACE insertion/deletion and 12 other polymorphisms on clinical outcomes and response to treatment in the LIFE study. Pharmacogenet. Genomics 20(2), 77-85 (2010).

16. Rimpelä JM, Kontula KK, Fyhrquist $\mathrm{F}$ et al. Replicated evidence for aminoacylase 3 and nephrin gene variations to predict antihypertensive drug responses. Pharmacogenomics 18(5), 445-458 (2017).

17. Hiltunen TP, Donner KM, Sarin AP et al. Pharmacogenomics of hypertension: a genome-wide, placebo-controlled cross-over study, using four classes of antihypertensive drugs. J. Am. Heart Assoc. 4(1), e001521 (2015).

18. Purcell S, Neale B, Todd-Brown K et al. PLINK: a tool set for whole-genome association and population-based linkage analyses. Am. J. Hum. Genet. 81(3), 559-575 (2007).

19. Stack AG, Hanley A, Casserly LF et al. Independent and conjoint associations of gout and hyperuricaemia with total and cardiovascular mortality. QJM 106(7), 647-658 (2013).

20. Borghi C, Rosei EA, Bardin $\mathrm{T}$ et al. Serum uric acid and the risk of cardiovascular and renal disease. J. Hypertens. 33(9), 1729-1741 (2015).

- Review article summarizing the role of uric acid in metabolic and cardiovascular diseases.

21. GTExPortal. www.gtexportal.org/home

22. The GTEx Consortium. Genetic effects on gene expression across human tissues. Nature 550(7675), 204-213 (2017).

23. Testa U, Pannitteri G, Condorelli GL. Vascular endothelial growth factors in cardiovascular medicine. J. Cardiovasc. Med. (Hagerstown) 9(12), 1190-1221 (2008).

24. Ristimäki A, Narko K, Enholm B, Joukov V, Alitalo K. Proinflammatory cytokines regulate expression of the lymphatic endothelial mitogen vascular endothelial growth factor-C. J. Biol. Chem. 273(14), 8413-8418 (1998).

25. Woodman R, Brown C, Lockette W. Chlorthalidone decreases platelet aggregation and vascular permeability and promotes angiogenesis. Hypertension 56(3), 463-470 (2010).

- In vitro experiment reporting the altered expression of $V E G F C$ in vascular smooth muscle cells after administration of thiazides.

26. Holmes K, Roberts OL, Thomas AM, Cross MJ. Vascular endothelial growth factor receptor-2: structure, function, intracellular signaling and therapeutic inhibition. Cell. Signal. 19(10), 2003-2012 (2007).

27. Connelly JJ, Shah SH, Doss JF et al. Genetic and functional association of FAM5C with myocardial infarction. BMC Med. Genet. 9, 33 (2008).

28. Sato J, Kinugasa M, Satomi-Kobayashi $S$ et al. Family with sequence similarity 5, member C (FAM5C) increases leukocyte adhesion molecules in vascular endothelial cells: implication in vascular inflammation. PLOS ONE 9(9), e107236 (2014).

29. National Center for Biotechnology Information, National Library of Medicine. dbGaP/database of genotypes and phenotypes (2017).

www.ncbi.nlm.nih.gov/projects/gap/cgi-bin/study.cgi?study_id=phs000375.v1.p1.

30. Smith ER, McMahon LP, Holt SG. Fibroblast growth factor 23. Ann. Clin. Biochem. 51(Pt 2), 203-227 (2014).

31. Sakoh T, Nakayama M, Tsuchihashi T et al. Associations of fibroblast growth factor 23 with urate metabolism in patients with chronic kidney disease. Metabolism 65(10), 1498-1507 (2016).

32. Gutierrez OM, Wolf M, Taylor EN. Fibroblast growth factor 23, cardiovascular disease risk factors and phosphorus intake in the health professionals follow-up study. Clin. J. Am. Soc. Nephrol. 6(12), 2871-2878 (2011).

33. Asicioglu E, Kahveci A, Arikan H, Koc M, Tuglular S, Ozener C. Fibroblast growth factor-23 levels are associated with uric acid but not carotid intima media thickness in renal transplant recipients. Transplant. Proc. 46(1), 180-183 (2014).

34. Anzilotti C, Pratesi F, Tommasi C, Migliorini P. Peptidylarginine deiminase 4 and citrullination in health and disease. Autoimmun. Rev. 9(3), 158-160 (2010). 
35. Bhatnagar V, Richard EL, Wu W et al. Analysis of ABCG2 and other urate transporters in uric acid homeostasis in chronic kidney disease: potential role of remote sensing and signaling. Clin. Kidney J. 9(3), 444-453 (2016). 